\title{
Experimental evaluation of polycrystalline diamond tool geometries while drilling carbon fiber-reinforced plastics
}

\author{
Y. Karpat • B. Değer • O. Bahtiyar
}

Received: 31 July 2013 / Accepted: 19 December 2013 /Published online: 5 January 2014

(C) Springer-Verlag London 2014

\begin{abstract}
Polycrystalline diamond (PCD) drills are commonly employed in carbon fiber-reinforced plastic (CFRP) drilling to satisfy hole quality conditions with an acceptable tool life and productivity. Despite their common use in industry, only a small number of studies have been reported on drilling CFRPs with PCD drills. In this study, drilling performances of three different PCD drill designs are investigated experimentally using thrust force, torque, and hole exit quality measurements. Results show that work material properties, drilling conditions, and drill design should all be considered together during the selection of process parameters, and the relationships among these factors are quite complex.
\end{abstract}

Keywords Drilling · Carbon fiber-reinforced plastics · Polycrystalline diamond

\section{Introduction}

The influences of globalization on international travel, including fuel prices and passenger demand for cheaper ticket prices, push manufacturers to produce lighter aircrafts. Employing advanced materials such as aluminum, titanium, and nickel alloys has contributed significantly to the weight reduction of aircrafts. However, Babikian et al. [1] showed that structural efficiency (operating empty weight/maximum takeoff weight) among all types of aircrafts produced between 1955 and 2000 decreased about $15 \%$ since the weight reductions due to

Y. Karpat $(\bowtie)$

Department of Industrial Engineering, Bilkent University,

Ankara 06800, Turkey

e-mail: ykarpat@bilkent.edu.tr

B. Değer · O. Bahtiyar

Turkish Aerospace Industries Inc., Ankara 06980, Turkey employing advanced materials have been offset by larger engine sizes, modifications in aircraft structures for better aerodynamics, and passenger requests such as personal entertainment systems. Recent developments in composite materials and their use in the aerospace industry help increase the structural efficiency of the aircrafts. In the new generation of aircrafts, the use of composites such as carbon fiber-reinforced plastics (CFRP) in structural parts has reached $40 \%$ of all materials. These CFRP parts have produced near net shape, which means rough machining operations are eliminated. However, drilling and some milling operations are still required to bring them to their final shapes. Drilling, one of the most common machining processes in aircraft manufacturing, is the subject of this paper.

CFRPs are known to be difficult to machine due to the abrasive nature of carbon fibers and low thermal conductivity of the plastic matrix. While machining CFRPs, heat generated at the cutting zone cannot be transferred away with chips as in metal cutting. Material removal is realized through a series of brittle fractures that depend on the fiber direction of the laminate. An extensive review of issues related to CFRP machining is presented in $[2,3]$. Under these conditions, rapid tool wear is common while drilling CFRP laminates even when polycrystalline diamond (PCD) [4] and diamondcoated carbide tools [5] are employed. Rapid tool wear results in increased drilling forces, which leads to delamination at the exit of the drilled holes. As an anisotropic and laminated material, CFRPs are very sensitive to delamination, which is considered to be the most important finished part quality measure. Hole diameter, another important quality measure, is closely related to the condition of the drill. As the drill wears out, its diameter decreases, which in turn affects the drilled hole diameter. Tool wear may also damage the interior surface of the drilled hole. In order to circumvent such problems, the condition of the drilling tools and drilling parameters must be closely monitored during production. 
Due to its popularity in the aerospace industry, CFRP drilling has already been the subject of many studies. Most of these have considered the influence of drilling conditions (drilling speed, feed, drill geometry) on delamination, drilling forces, and tool wear [6-13]. In these studies, it has been shown that feed and tool geometry are the two most important input parameters affecting the quality of drilled holes. It is recommended to set feed at low values, especially when drilling unidirectional (UD) CFRPs, in order to decrease thrust forces and thus decrease the likelihood of delamination. Drill geometries that distribute thrust forces towards the drill periphery are recommended, and special drill geometries have been proposed to satisfy this requirement [11, 12]. Use of back-up plates, drilling with a pilot hole, and variable feed rate drilling strategy is also recommended to decrease delamination [13-15]. Material properties of CFRPs are also known to be influential. Fabric woven type CFRP laminates are known to be more resistant to delamination than the unidirectional type CFRPs. It must be noted that machining performance and material characteristics are directly related, and
CFRP material properties may vary significantly depending on the carbon fiber diameter, type of resin, volumetric ratio of carbon fiber, curing conditions, etc.

PCD tool material combines high abrasion resistance, thermal conductivity, hardness, and impact toughness. Sharp cutting edges can be obtained due to the fine grain size of the PCD; however, coarse PCD grains help improve wear resistance. Due to their favorable properties, PCD drills are commonly employed in industry. However, there have been relatively few studies on the influence of PCD drill geometry on drilling process outputs. This study considers drilling of UDCFRPs with PCD drills. The performances of three PCD drills with different geometries have been investigated experimentally.

The paper is organized as follows: Firstly, the experimental setup and drilling conditions are explained. Secondly, thrust force and torque measurements during drilling with three different PCD drills are analyzed and the hole exit performances of drills are compared. Thirdly, edge conditions of the cutting edges after drilling have been investigated. Finally,
Fig. 1 Double point angle PCD tool designs. a T1. b T2. c T3
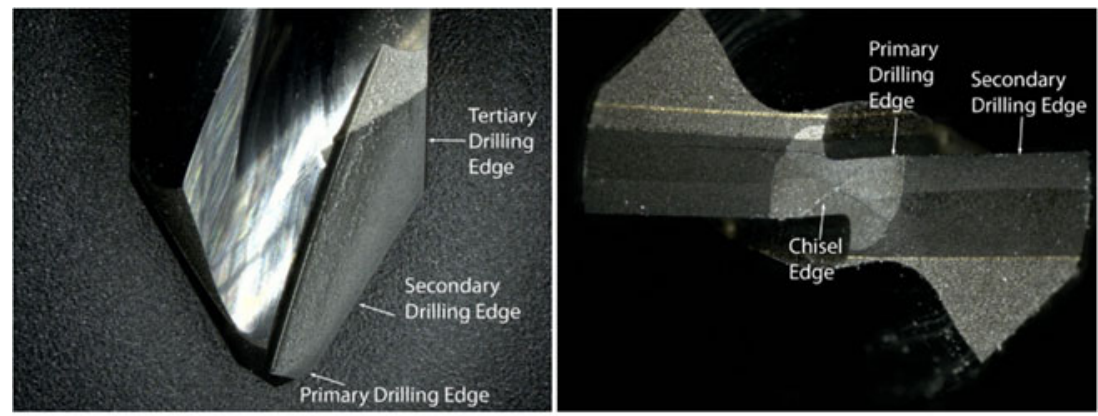

a

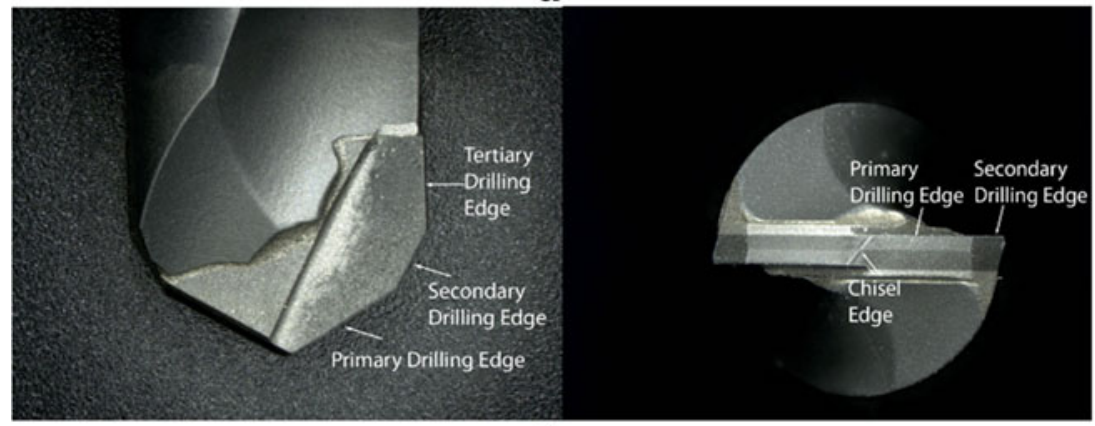

b

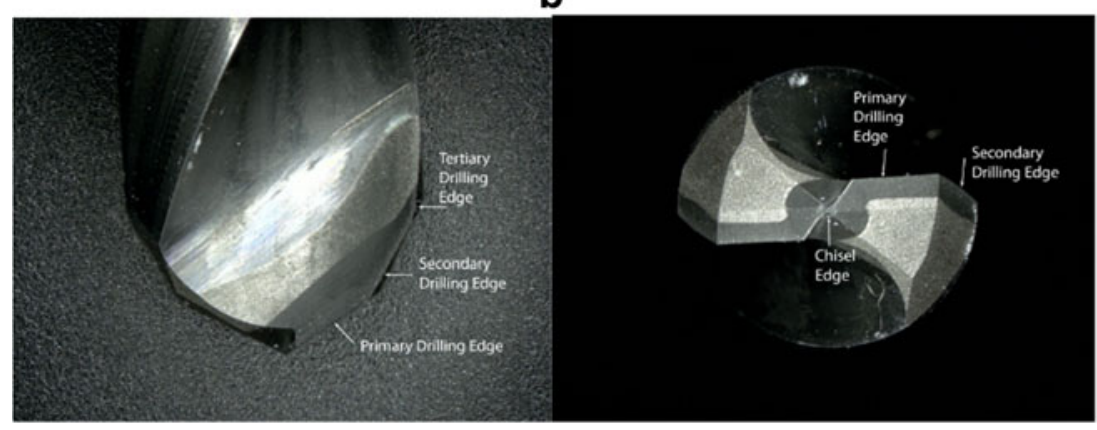

C 


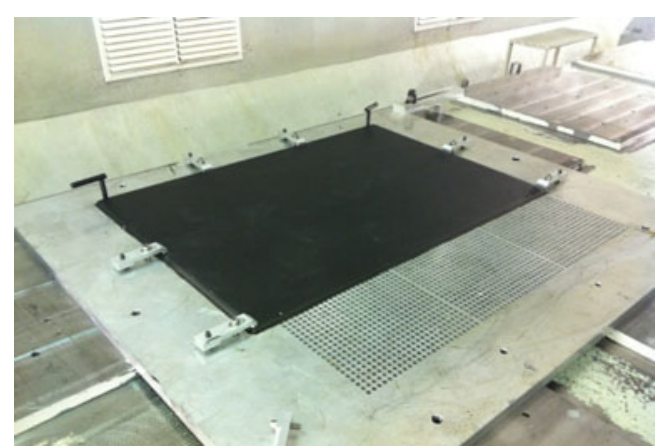

Fig. 2 CFRP plate used in drilling experiments with the aluminum back plate

drilling characteristics of three different PCD drills are compared and discussed.

\section{Experimental setup}

Three different double point angle PCD drills with distinct designs are considered in the experiments as shown in Fig. 1 The tool tip images were captured using a digital microscope (Keyence VHX 1000). All tools have double (primary and secondary) tip angles. The tool on the top (Fig. 1a) is designated as T1 and its secondary drilling edge is considerably larger than its primary drilling edge. The drill in the middle (Fig. 1b) is designated as T2, and compared to T1, it has a different design where the primary drilling edge is considerably larger than the secondary drilling edge. The drill on the bottom (Fig. 1c) is designated as T3; it also has a double point angle geometry, but it is fabricated in twist drill form with a helix angle of $30^{\circ}$. The same figure also shows the chisel edge designs of the drills. T2 has a considerably smaller chisel edge than that of T1 and T3. All designs have a tertiary edge which does not contribute to thrust forces during drilling, but which affects drilling torques. Drilling experiments were conducted on a five-axis precision CNC machining center with maximum 24,000 rpm rotational speed. The machining center is equipped with the air conditioning and air filtering systems required for CFRP machining. Machining was performed under wet conditions, where emulsion type coolant was used.

The test setup is shown in Fig. 2. A plate made out of aluminum alloy with $8-\mathrm{mm}$ diameter holes was used as a backing plate to drill $6.4-\mathrm{mm}$ diameter holes. The drilling forces and torques were measured by a Kistler 9123 rotating dynamometer and its charge amplifier. The collected data

Table 1 Experimental conditions

\begin{tabular}{lll}
\hline $\begin{array}{l}\text { Rotational speed } \\
(\mathrm{rpm})\end{array}$ & $\begin{array}{l}\text { Laminate thickness } \\
(\mathrm{mm})\end{array}$ & $\begin{array}{l}\text { Feed per revolution } \\
(\mathrm{mm} / \mathrm{rev})\end{array}$ \\
\hline 5,000 & 10 & $0.01-0.06$ \\
\hline
\end{tabular}

Table 2 Material properties of CFRP laminates

\begin{tabular}{lllll}
\hline Material & $\begin{array}{l}\text { Fiber } \\
\text { volume } \\
(\% v / v)\end{array}$ & $\begin{array}{l}\text { Strength } \\
(\mathrm{MPa})\end{array}$ & $\begin{array}{l}\text { Modulus } \\
(\mathrm{GPa})\end{array}$ & $\begin{array}{l}\text { Density } \\
\left(\mathrm{g} / \mathrm{cm}^{3}\right)\end{array}$ \\
\hline $\begin{array}{l}\text { Intermediate modulus } \\
\text { carbon fiber-reinforced } \\
\text { epoxy resin unidirectional } \\
\text { tape }^{\mathrm{a}}\end{array}$ & 59 & 2,690 & 165 & 1.58 \\
\hline
\end{tabular}

${ }^{\mathrm{a}}$ Mechanical properties are for $0^{\circ}$ tensile properties at room temperature

were processed on a personal computer. Table 1 shows the range of drilling conditions used in the experiments. All drilling experiments were performed on the same CFRP material. Rotational speed is kept constant at 5,000 rpm to obtain an acceptable level of cutting speed without exciting the dynamics of the rotational force dynamometer. A CFRP laminate of $10-\mathrm{mm}$ thickness was used in the experiments. The feed rate range covers 50 to $300 \mathrm{~mm} / \mathrm{min}$.

Intermediate modulus UD-CFRP laminates were produced for drilling tests. The CFRP laminates have 0.14-mm ply thickness, with UD-CFRP configuration of $0 \% / 45^{\circ} / 90^{\circ} /-45^{\circ} /$ $0^{\circ}$ with an equal number of plies in each direction. Table 2 shows the mechanical properties of the UD-CFRP laminates.

\section{Analysis of thrust force and torque measurements during drilling with double point angle PCD drills}

A generalized double point angle drill geometry is shown in Fig. 3. In this figure, region $O$ represents the chisel edge with length $L$, OA shows the primary drilling region, $\mathrm{AB}$ shows the secondary drilling region, and $\mathrm{BC}$ shows the tertiary drilling edge. The drill design parameters are the length $(L)$ and angle $(\gamma)$ of the chisel edge, length of OA $\left(L_{\mathrm{OA}}\right)$, length of BC $\left(L_{\mathrm{BC}}\right)$, and the tool tip angles $\alpha$ and $\beta$. In the aerospace industry, hole diameters are standardized; therefore, the tool diameter $(D=$

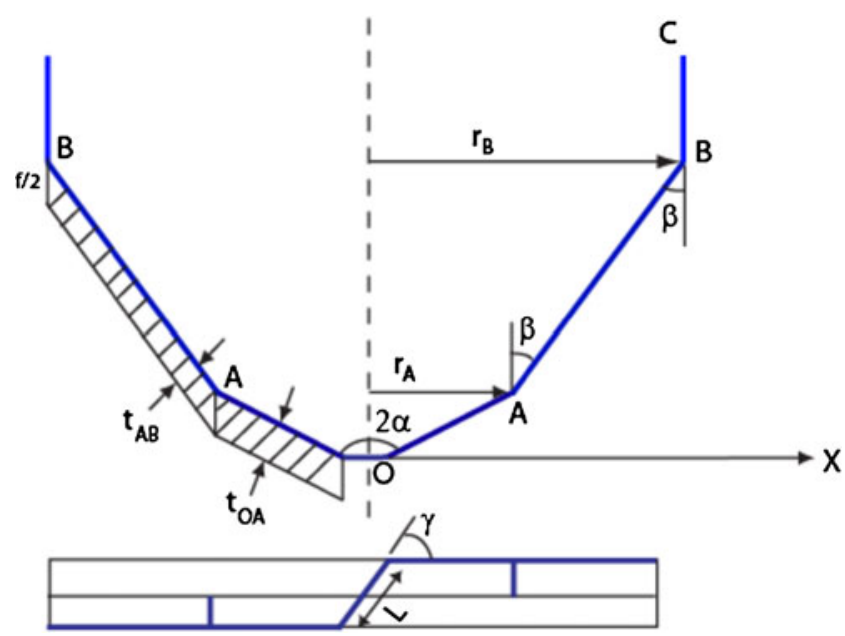

Fig. 3 Double tip point angle PCD drill geometry 
Table 3 Drill geometry measurements

\begin{tabular}{llllllllll} 
Tool & $\begin{array}{l}\text { Diameter, D } \\
\left(2 r_{\mathrm{B}}\right)(\mathrm{mm})\end{array}$ & $\begin{array}{l}2 \alpha \\
\left({ }^{\circ}\right)\end{array}$ & $\begin{array}{l}\beta \\
\left({ }^{\circ}\right)\end{array}$ & $\begin{array}{l}L \\
(\mu \mathrm{m})\end{array}$ & $\begin{array}{l}\gamma \\
\left({ }^{\circ}\right)\end{array}$ & $\begin{array}{l}r_{\mathrm{A}} \\
(\mathrm{mm})\end{array}$ & $\begin{array}{l}L_{\mathrm{OA}} \\
(\mathrm{mm})\end{array}$ & $\begin{array}{l}L_{\mathrm{AB}} \\
(\mathrm{mm})\end{array}$ & $\begin{array}{l}L_{\mathrm{BC}} \\
(\mathrm{mm})\end{array}$ \\
\hline $\mathrm{T} 1$ & 6.4 & 120 & 30 & 1,250 & 37 & 0.82 & 0.46 & 4.4 & 2 \\
$\mathrm{~T} 2$ & 6.4 & 120 & 30 & 800 & 50 & 2.5 & 2.5 & 1.4 & 2 \\
$\mathrm{~T} 3$ & 6.4 & 120 & 25 & 1,600 & 54 & 2.2 & 2 & 1.7 & 1
\end{tabular}

$2 r_{\mathrm{B}}$ ) can be assumed as known. Table 3 summarizes geometry measurements for T1, T2, and T3 drill designs. Measurements are obtained through a digital microscope.
For a given tool diameter $\left(D=2 r_{\mathrm{B}}\right)$, known tool tip angles ( $\alpha$ and $\beta$ ), primary edge length $\left(L_{\mathrm{OA}}\right)$, chisel edge length $(L)$, and angle $(\gamma)$, Eq. 1 can be used to calculate the length of the secondary drilling region $\left(L_{\mathrm{AB}}\right)$ as a dependent variable.

$L_{\mathrm{AB}}=\frac{1}{\sin \beta}\left(r_{\mathrm{B}}-L_{\mathrm{OA}} \sin \alpha-\frac{L \cos \gamma}{2}\right)$

The total thrust force $\left(F_{\mathrm{z}}\right)$ and torque $(T)$ acting on the drill during hole entry can be represented with Eq. 2 . The first term $\left(F_{\mathrm{z}-\mathrm{ch}}\right)$ represents the influence of the chisel edge, the second term represents the contribution of the primary drilling edge
Fig. 4 a Stages of a drilling process with a double point angle PCD drill. b Thrust force and torque measurements for $\mathrm{T} 1$ at $5,000 \mathrm{rpm}$ and $20 \mu \mathrm{m} / \mathrm{rev}$ feed

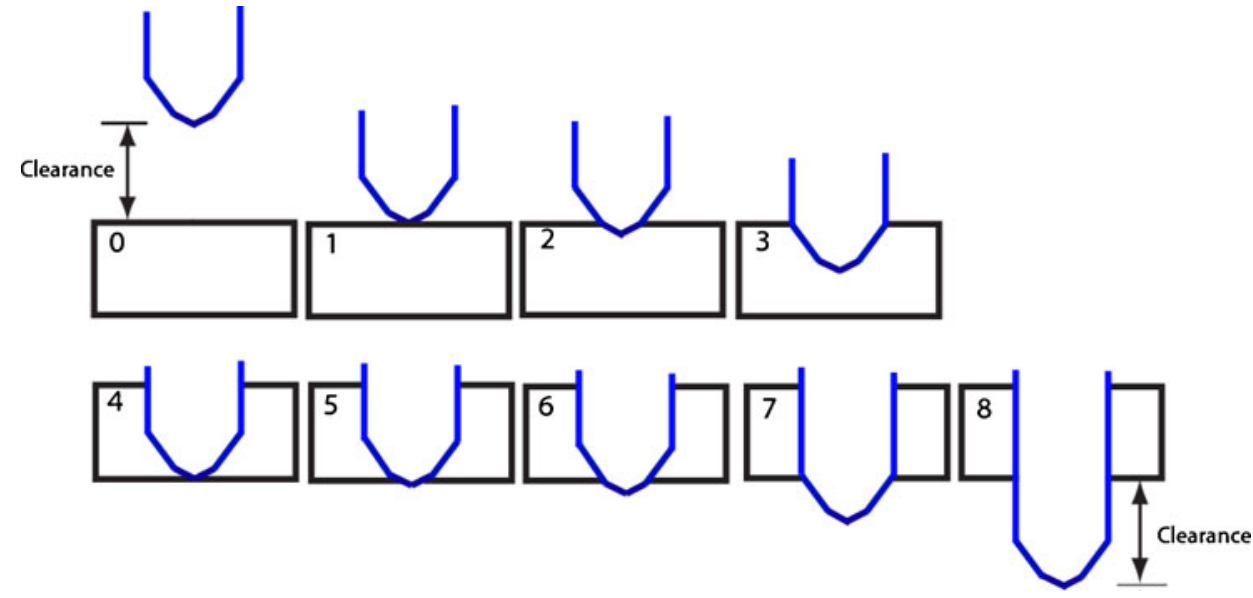

a

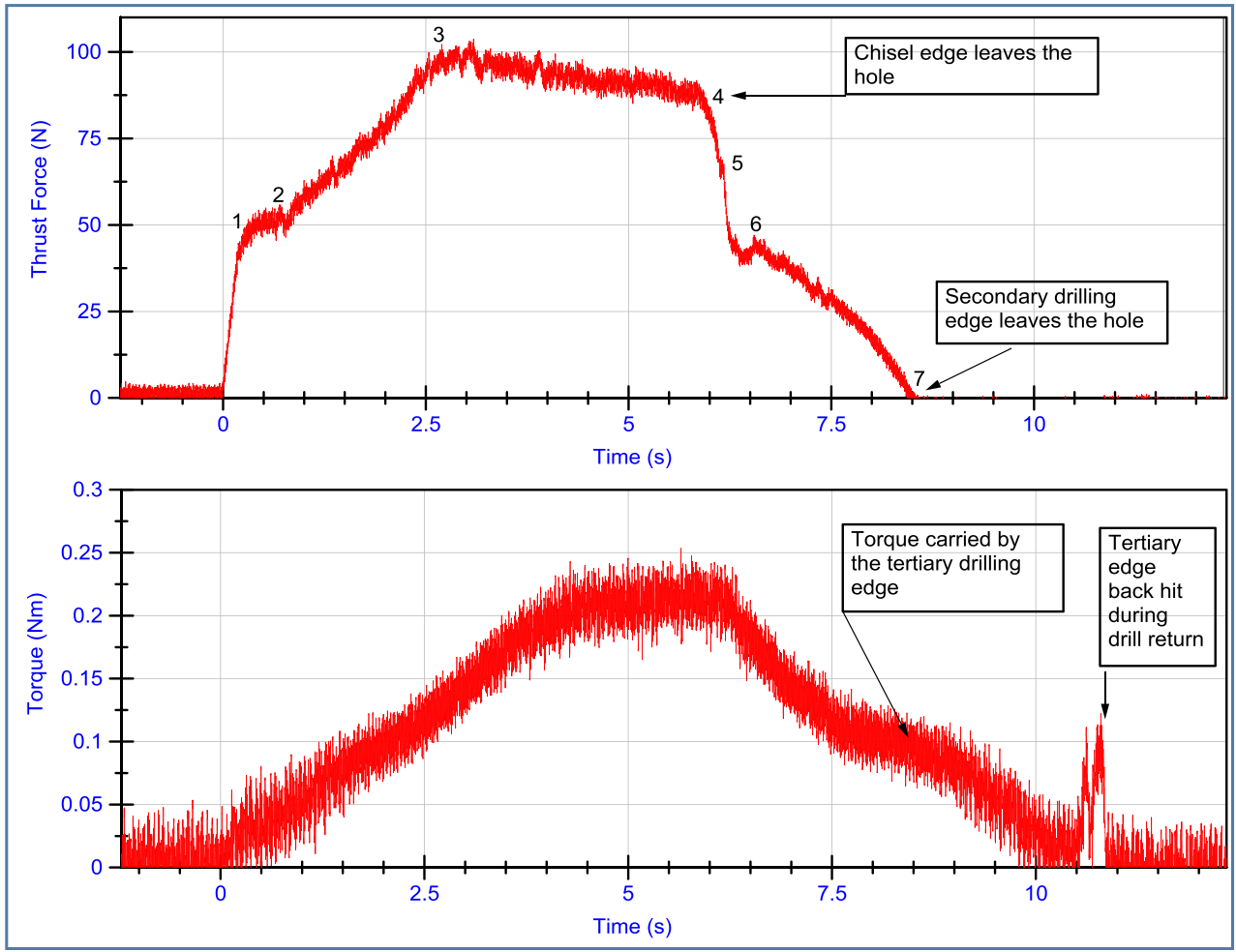

b 
$\left(F_{\mathrm{z}-\mathrm{OA}}\right)$, and the last term represents the role of the secondary drilling edge $\left(F_{\mathrm{z}-\mathrm{AB}}\right)$ on the total thrust force. The effect of the tertiary region $(\mathrm{BC})$ on the thrust forces is neglected. A similar equation can also be written for total drilling torque $(T)$. The chisel edge is known to carry a small amount of torque; therefore, it is neglected.

$\sum F_{\mathrm{z}}=F_{\mathrm{z} \_\mathrm{ch}}+F_{\mathrm{z} \_\mathrm{OA}_{1}}+F_{\mathrm{z} \_\mathrm{AB}}$
$\sum T=T_{\mathrm{OA}}+T_{\mathrm{AB}}+T_{\mathrm{BC}}$
Due to the double point angle design of the drilling tool, the uncut chip thickness $(t)$ is different in $\mathrm{OA}$ and $\mathrm{AB}$ as shown in Fig. 3 and can be calculated with Eq. 3 where $f$ is the feed value.
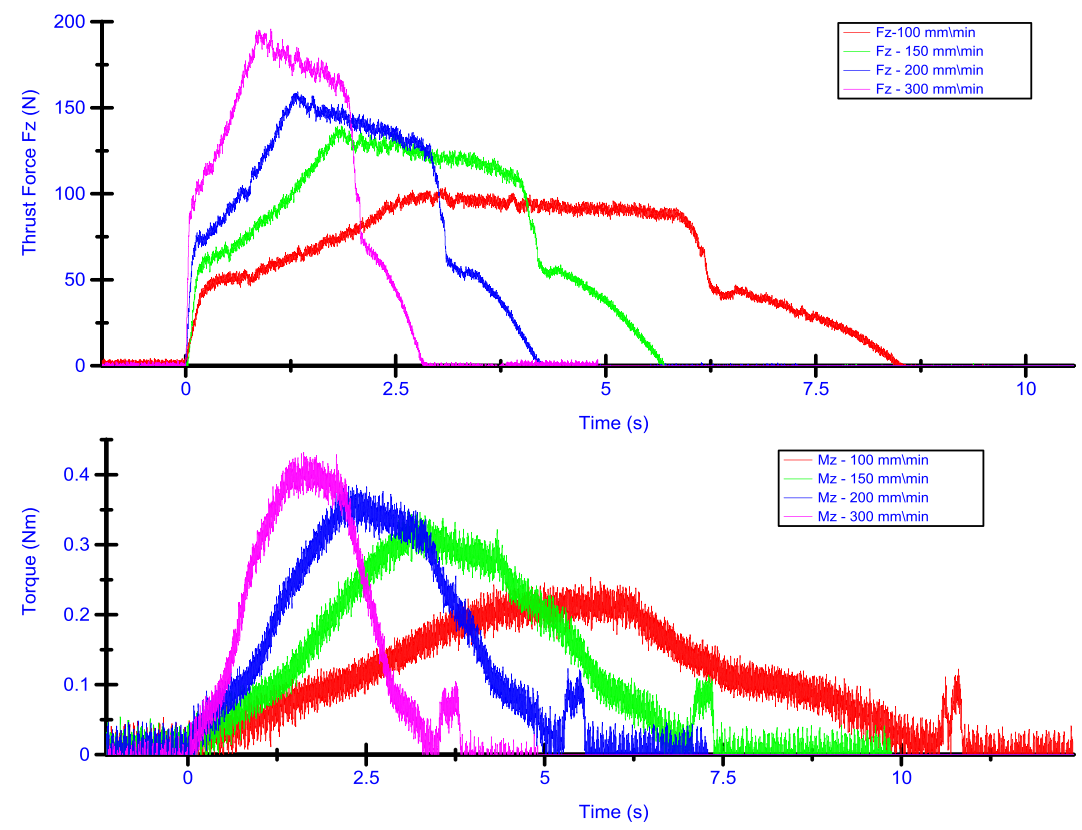

a
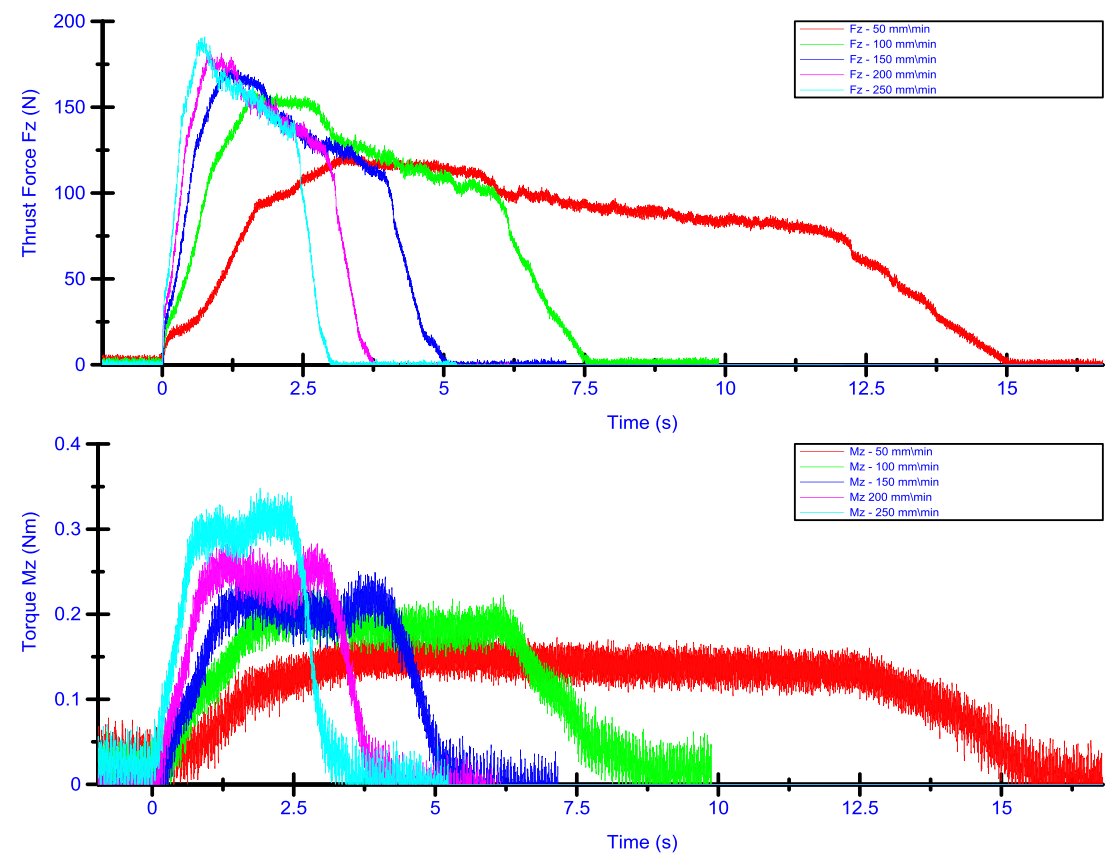

b

Fig. 5 Thrust force and torque measurements for a T1, b T2, and $\mathbf{c}$ T3 at 5,000 rpm 

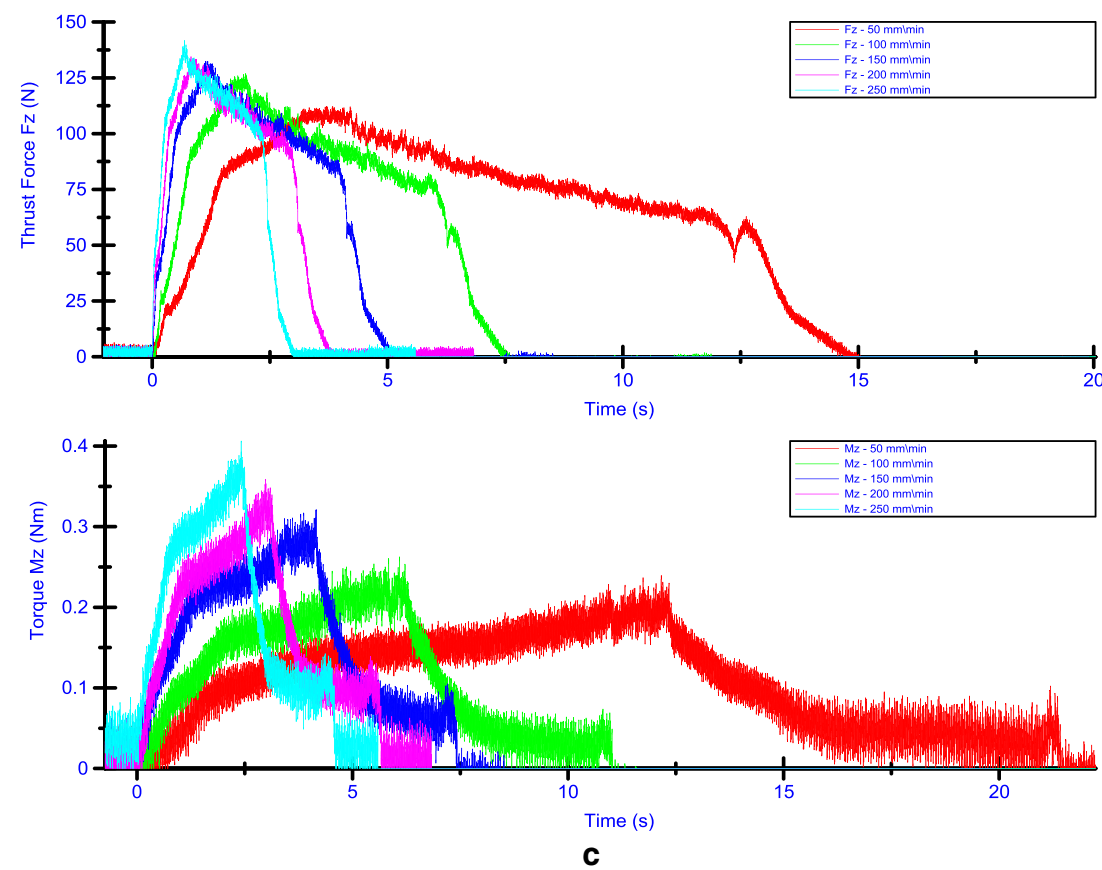

Fig. 5 continued.

The uncut chip area under primary (OA) and secondary (AB) edges (shown as hatched areas in Fig. 3) can be approximated by multiplying the length of the edge with the uncut chip thickness at each region. It must be noted that decreasing the tool tip angle $\beta$ results in longer edge length due to constant tool diameter.

The force and torque measurements obtained during drilling reveal important information about the influence of tool geometry and drilling process parameters on the CFRP drilling process. This information, along with hole quality measurements, can be used to set process parameters, to monitor tool wear, and to improve drill geometries. Figure 4a illustrates different phases (points $0-7$ ) of the drilling process when a double point angle PCD tool is employed. Figure 4b shows measured thrust force and torque variations for drill $\mathrm{T} 1$ at 5,000 rpm and $20 \mu \mathrm{m} / \mathrm{rev}$ feed. The drilling process starts from a position (point 0 ) with enough distance so that the drill reaches the required feed rate before entering the hole; therefore, a constant feed rate is maintained until the end of the drilling process (point 7).

The first point (1) on the thrust force curve corresponds to the location where the chisel edge of the drill enters the material (1 in Fig. 4a). The second point (2) corresponds to the location where the primary cutting edge of the drill enters the hole. While thrust force increases dramatically in this region, the increase in torque is quite small. As the secondary drilling zone enters the hole (point 3 ), the rate of increase in thrust force decreases since drilling is performed with lower angle $(\beta)$ which decreases the uncut chip thickness. Peak thrust force is reached at the end of the secondary drilling zone (point 3). Thrust force slightly decreases towards the hole exit due to the decreasing number of plies (point 4). It must be noted that around this point, the torque reaches its peak value. The torque difference between points 3 and 4 is due to contact between the tertiary drilling edge and the material. As soon as the chisel edge (point 5) and primary drilling edge (point 6) leave the cut, thrust force decreases rapidly with a rate similar to that which is observed at the hole entry (points 1-2). It must be noted that the torque stays almost the same between points 4 and 6 since the secondary cutting edge, which carries most of the torque, is still in contact with the material. The thrust force and torque decrease continuously between points 4 and 8 until the drill completely leaves the cut. During retraction of the drill, the tertiary edge may contact the drilled hole, which corresponds to a torque jump as observed in Fig. 4b. It must be noted that for known drill geometry, laminate thickness, and feed rate, the characteristic thrust force and torque values through points 1 to 6 can be obtained from measurements. Figure 5 shows the time history of thrust force and torque measurements as a function of feed rates obtained during drilling for drills $\mathrm{T} 1, \mathrm{~T} 2$, and $\mathrm{T} 3$.

The thrust force and torque variation during hole entry (points 1-3) can be used to compare the drilling characteristics of drills T1, T2, and T3. Distribution of thrust force and torque among chisel edge and primary and secondary drilling edges can be obtained as a function of feed. It is clear from these measurements (Fig. 5) that drill geometry influences the progress of thrust forces and torques during drilling, at both entry and exit points. From these measurements, it can be seen that drill T2 yielded larger thrust forces but lower torque measurements than drills $\mathrm{T} 1$ and $\mathrm{T} 3$. 


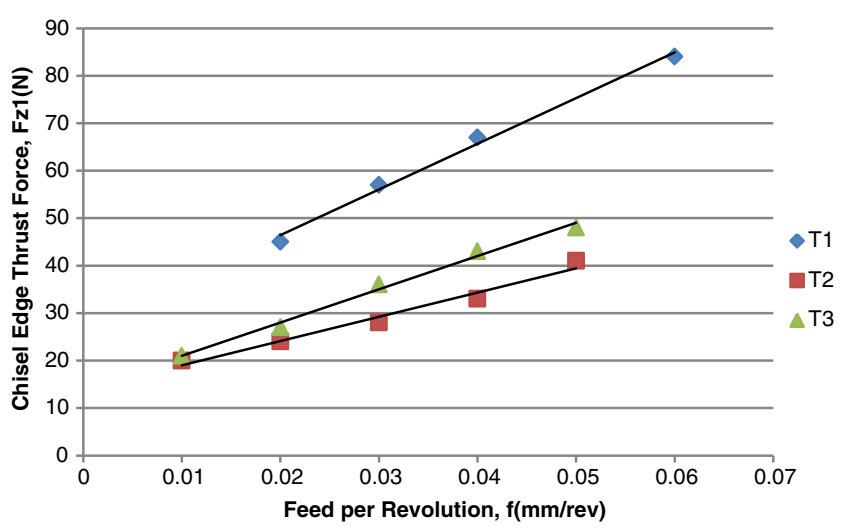

Fig. 6 Chisel edge thrust force $\left(F_{\mathrm{z} 1}\right)$ measurements as a function of feed per revolution

As mentioned earlier, using drill geometry measurements, it is possible to obtain characteristic force and torque measurements for each drill from Fig. 5. The chisel edge thrust forces (point 1 in Fig. 4a) are compared in Fig. 6 as a function feed per revolution. Drill T2 yielded lower thrust forces, thanks to its small chisel edge length.

It must be noted that $\mathrm{T} 2$ and $\mathrm{T} 3$ exhibited similar thrust forces, while the chisel edge length of T3 is almost twice as large as that of T2. Drill T1 yielded the largest thrust forces among all tested drills. The chisel edge geometry of T3, which employs a rake angle, is obviously more effective than $\mathrm{T} 1$ based on chisel edge thrust forces shown in Fig. 6. The chisel edge geometry of drill T1 as shown in Fig. 7 is different than
$\mathrm{T} 2$ and $\mathrm{T} 3$ in the sense that it seems to form a single cutting edge that combines with the primary drilling edge as a spear head.

In order to calculate and compare the thrust force and torques in the primary drilling edge, the chisel edge thrust forces and torques corresponding to point 1 are subtracted from the measurements obtained at point $2\left(F_{\mathrm{z}_{-} \mathrm{OA}}=F_{\mathrm{z} 2}-F_{\mathrm{z} 1}\right)$. Similarly, the secondary drilling edge thrust force is calculated by subtracting the primary edge force from the peak force $\left(F_{\mathrm{z} \_\mathrm{AB}}=F_{\mathrm{z} 3}-F_{\mathrm{z} 2}\right)$. The measurements are given as thrust force per edge versus feed per edge (all drills have two drilling edges) as shown in Eq. 4.

$$
\begin{aligned}
& F_{\mathrm{z}-\mathrm{OA}}=\frac{F_{\mathrm{z} 2}-F_{\mathrm{z} 1}}{2} \\
& F_{\mathrm{z}-\mathrm{AB}}=\frac{F_{\mathrm{z} 3}-F_{\mathrm{z} 2}}{2}
\end{aligned}
$$

In order to compare thrust force and cutting force distribution among drilling edges, calculated forces are divided by corresponding uncut chip area as a function of feed. While calculating specific cutting force distribution, the midpoint distance of each drilling edge to the tool center is used to convert torque to cutting force $[9,16]$. The necessary equations are given in Eqs. 5, 6, and 7.

$$
A_{\mathrm{OA}}=r_{\mathrm{OA}}\left(\frac{f}{2}\right), \quad A_{\mathrm{AB}}=\left(r_{\mathrm{OB}}-r_{\mathrm{OA}}\right)\left(\frac{f}{2}\right)
$$

Fig. 7 Chisel edge designs of drills a $\mathrm{T} 1$ and $\mathbf{b} \mathrm{T} 3$
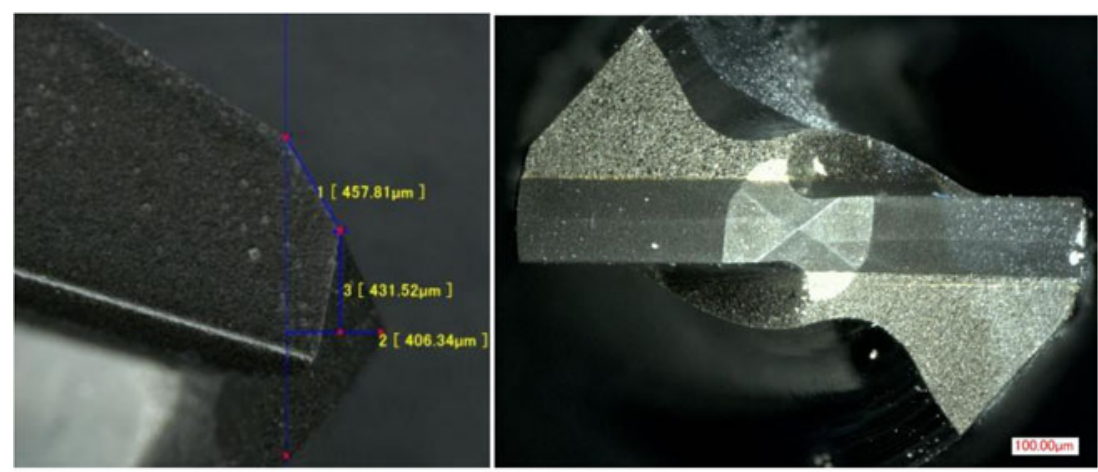

a
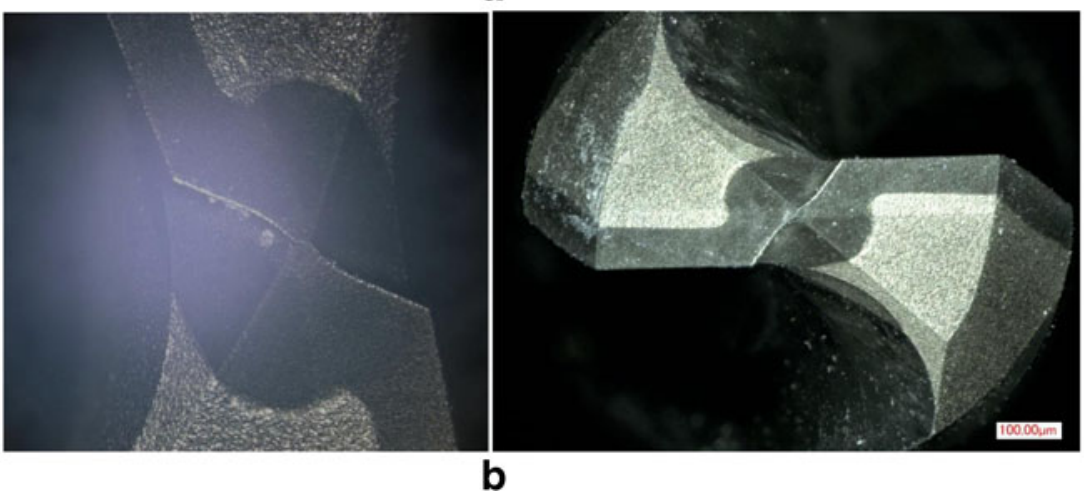
$K_{t-\mathrm{OA}}=\frac{F_{z-\mathrm{OA}}}{A_{\mathrm{OA}}}, \quad K_{t-\mathrm{AB}}=\frac{F_{\mathrm{z}-\mathrm{AB}}}{A_{\mathrm{AB}}}$

$K_{\mathrm{c}-\mathrm{OA}}=\frac{\left(T_{2}-T_{1}\right) / 2}{\left(\frac{r_{\mathrm{OA}}}{2}\right) A_{\mathrm{OA}}}, \quad K_{\mathrm{c}-\mathrm{AB}}=\frac{\left(T_{3}-T_{2}\right) / 2}{\left(\frac{r_{\mathrm{OA}}+r_{\mathrm{OB}}}{2}\right) A_{\mathrm{AB}}}$

The results are shown in Figs. 8 and 9. In drills T2 and T3, a more homogenous distribution of thrust forces between primary and secondary drilling edges is obtained, whereas drill T1 stress distribution on the chisel edge is larger than other edges. In terms of torque, for drill $\mathrm{T} 1$, almost all the torque is carried by the secondary drilling edge, whereas drills $\mathrm{T} 2$ and $\mathrm{T} 3$ distribute the torque evenly between the edges. It must be noted that cutting force distribution between edges changes slightly as feed increases.

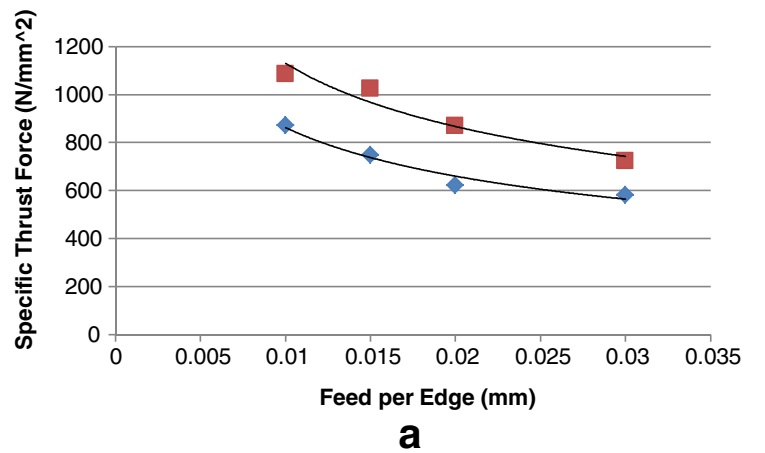

$O A$

$\mathrm{AB}$

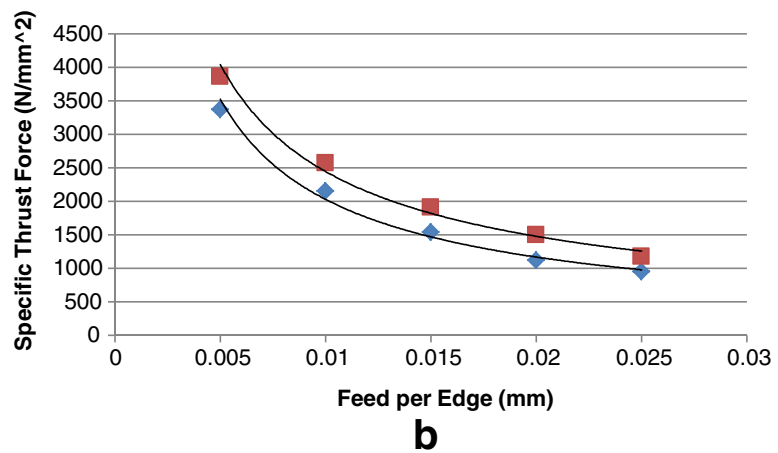

$\bullet \mathrm{OA}$ $\square \mathrm{AB}$

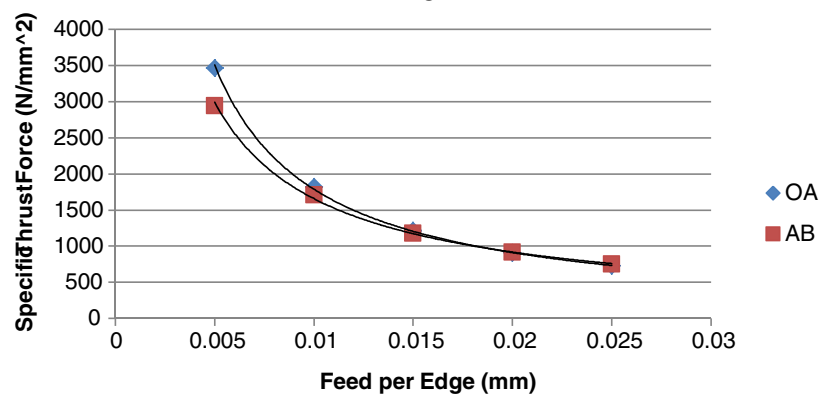

C

Fig. 8 Specific thrust force variation as a function of feed for drills a T1, b $\mathrm{T} 2$, and $\mathbf{c} \mathrm{T} 3$

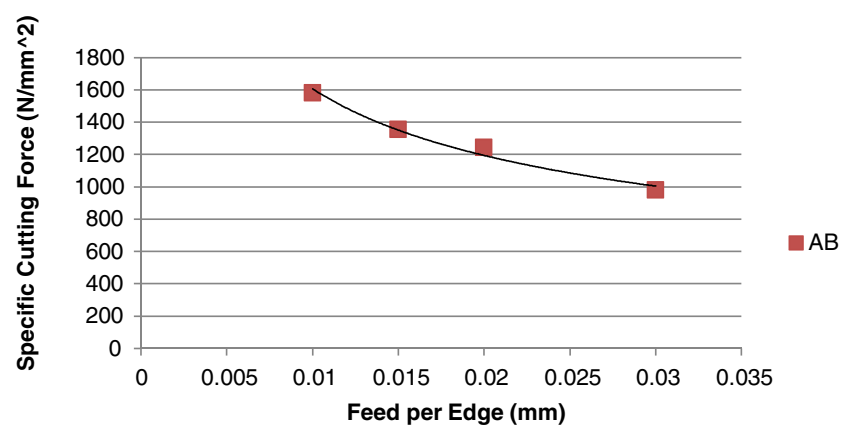

a

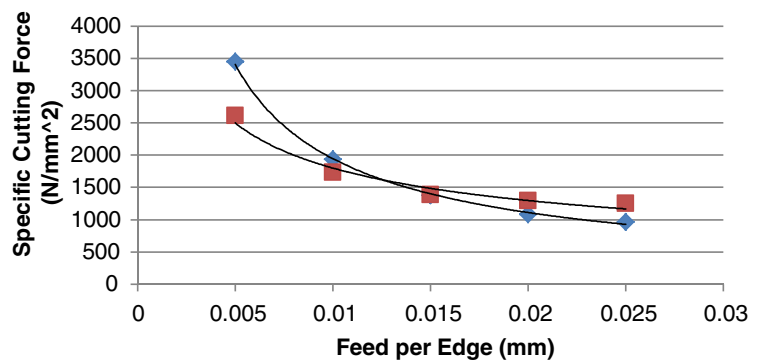

$\mathrm{AB}$

b

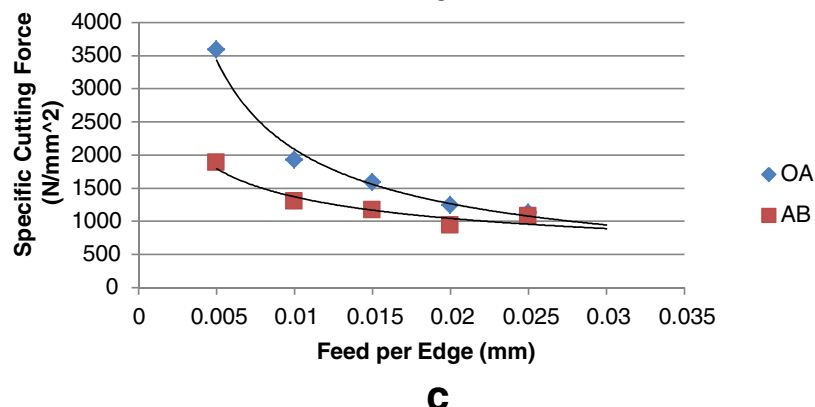

Fig. 9 Specific cutting force variation as a function of feed for drills a T1, b $\mathrm{T} 2$, and $\mathbf{c} \mathrm{T} 3$

\section{Investigation of hole exit quality}

Delamination is an important consideration in drilling CFRPs. The load-carrying capability of the laminates significantly decreases due to separation of plies. The thrust forces at the last ply of the laminate are considered to be responsible for delamination. The underlying mechanism is believed to be the indentation effect caused by the drill chisel edge. The level of thrust force at the hole exit leading to delamination is defined as critical thrust force $[11-15,17,18]$. The influence of predrilling on delamination was considered, and it was shown that pre-drilled pilot holes help reduce delamination $[14,15]$. Lachaud [17] proposed an analytical model to predict the critical thrust force based on material properties of the composite material. Hocheng and Tsao [12] considered different drill geometries and calculated critical thrust force expressions for each of them. They also evaluated the performance of the drills based on Taguchi analysis [19]. They concluded that drills that distribute the loads evenly on the drill periphery perform better and lower feeds help reduce thrust forces at the 
Feed

$20 \mu \mathrm{m} / \mathrm{rev}$

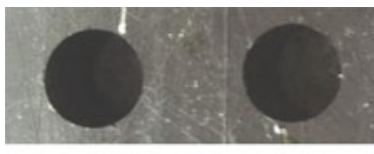

$30 \mu \mathrm{m} / \mathrm{rev}$

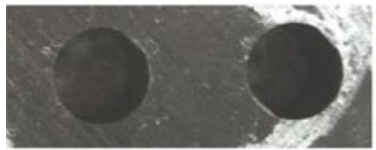

$40 \mu \mathrm{m} / \mathrm{rev}$

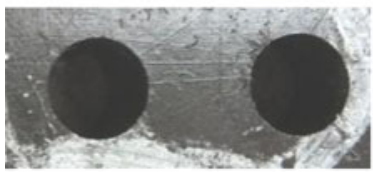

$50 \mu \mathrm{m} / \mathrm{rev}$

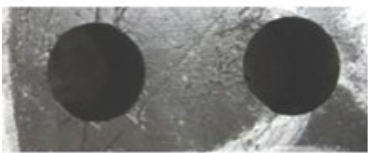

$60 \mu \mathrm{m} / \mathrm{rev}$
$\mathrm{T} 2$
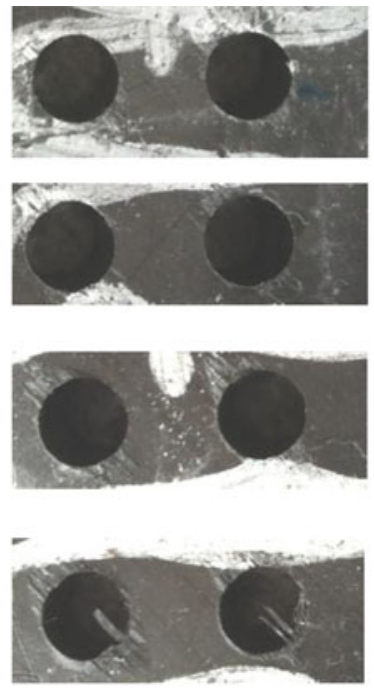

T3
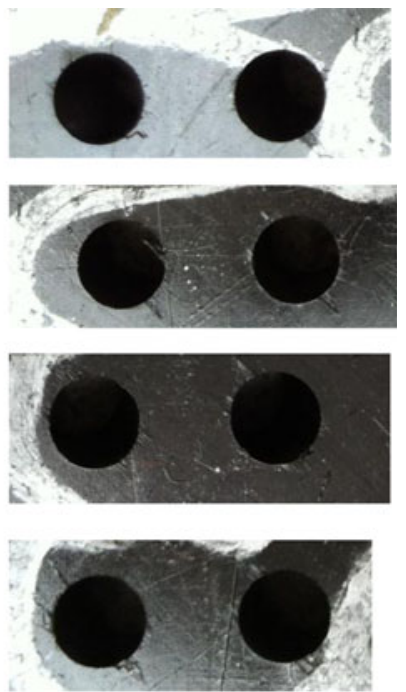

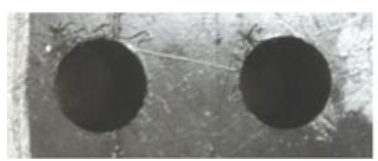

Fig. 10 Hole exits obtained with T1, T2, and T3

hole exit and hence the likelihood of delamination. Durao et al. [18] also conducted experiments on different drill geometries and also showed that low feed helps reduce the thrust forces at the hole exit but also increases the tool temperatures, which induces tool wear and subsequently leads to poor performance of the drill. They found that the twist drill, with $120^{\circ}$ point angle, yields the highest thrust forces at the hole exit, but it exhibited the best performance in terms of delamination.

Several procedures have been proposed for measuring delamination. One widely accepted delamination measure considers the ratio of the imaginary diameter drawn around
Fig. 11 a Phases of the hole exit sequence. b Measured thrust forces for each drill at point I

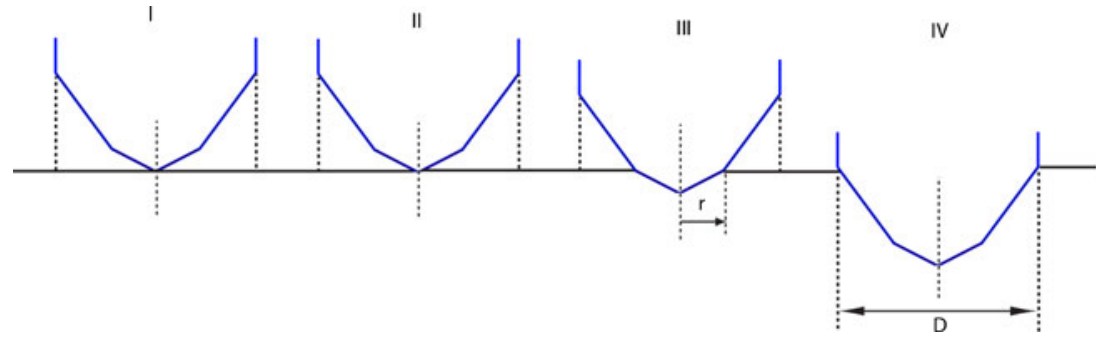

a

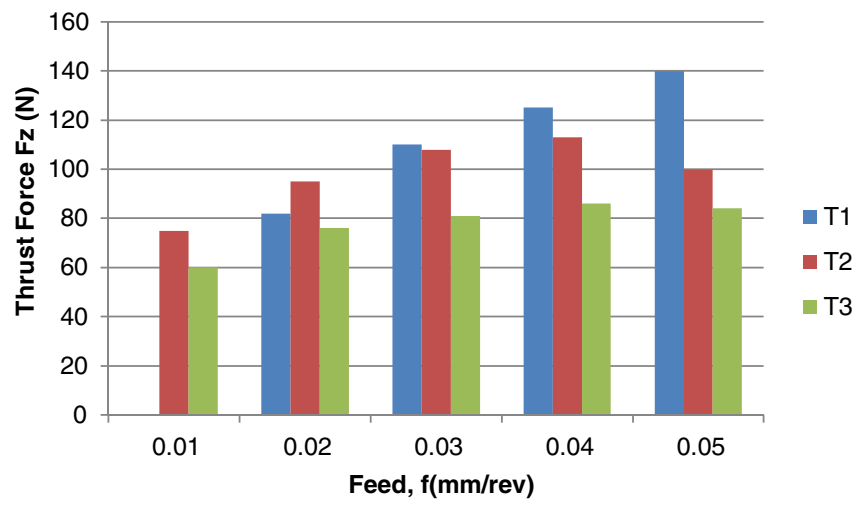

b 
the delaminated zone to the original hole diameter [6-8]. In this study, a visual examination of the hole exits are performed. Hole entry delamination was not observed during drilling experiments. Figure 10 shows the hole exits obtained after drilling tests with T1, T2, and T3. New drills were used at the beginning of each experiment.

The performance measure is defined as the ability to drill delamination-free holes at higher feeds, since drilling at higher feeds results in better productivity. According to Fig. 10, holes with no significant quality defects can be drilled at $40 \mu \mathrm{m} / \mathrm{rev}$ with $\mathrm{T} 1$ and $\mathrm{T} 3$, whereas the limiting feed value for $\mathrm{T} 2$ is $20 \mu \mathrm{m} / \mathrm{rev}$. Therefore, based on the defined performance measure, drills T1 and T3 outperform T2. Figure 11a shows the hole exit sequence of a double point angle PCD drill. The process is divided into four phases. The point I corresponds to the location of the chisel edge of the drill at the last ply of the laminate. It is followed by point II, where the chisel edge leaves the hole. Points III and IV correspond to primary and secondary drilling edges exiting the hole.

Figure $11 \mathrm{~b}$ shows the measured thrust forces at point $\mathrm{I}$. Based on the measurements, the critical thrust force for $\mathrm{T} 2 \mathrm{can}$ be considered to be around $95 \mathrm{~N}$ at $20 \mu \mathrm{m} / \mathrm{rev}$ feed value. However, for $\mathrm{T} 1$ and $\mathrm{T} 2$, critical thrust forces can be considered as 140 and $86 \mathrm{~N}$, respectively, at $50 \mu \mathrm{m} / \mathrm{rev}$ feed. The results show that drill geometry and feed affect the value of critical thrust force, but low thrust forces do not guarantee delamination-free holes. These results agree with the findings reported in [18].

Figure 11a also shows the projected hole area. Measured thrust forces (given in Fig. 5) at each point can be divided to the projected hole area to calculate normal stress variation during hole exit. Equation 8 can be used to calculate the projected normal stresses.

$S_{\mathrm{I}-\mathrm{IV}}=\frac{F_{\mathrm{z}}}{\pi\left(\frac{D^{2}}{4}-r^{2}\right)}$

As soon as the chisel edge leaves the hole at point II, the area of the chisel edge is subtracted from the projected hole area and the normal stress can be calculated. The same calculation is repeated for the case where the primary drilling region exits the hole at point III. It must be noted that drills have different chisel and primary and secondary edge lengths; therefore, the influence of drill geometry combined with the measured thrust forces is reflected on the normal stress calculations. No normal stress is applied to the workpiece when the secondary edge leaves the hole at point IV. Figure 12 compares the normal stresses applied to the workpiece during the hole exit sequence for $\mathrm{T} 1, \mathrm{~T} 2$, and $\mathrm{T} 3$.

It can be clearly seen that drills $\mathrm{T} 1$ and $\mathrm{T} 2$ apply more normal stress than $\mathrm{T} 3$ at the beginning of the hole exit

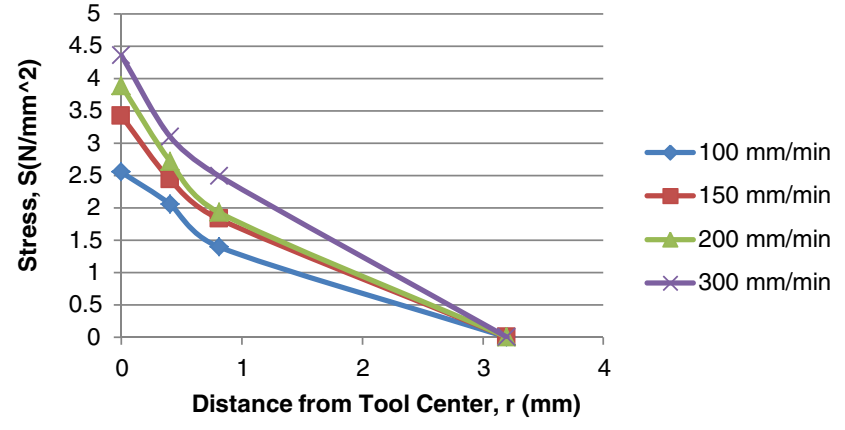

a
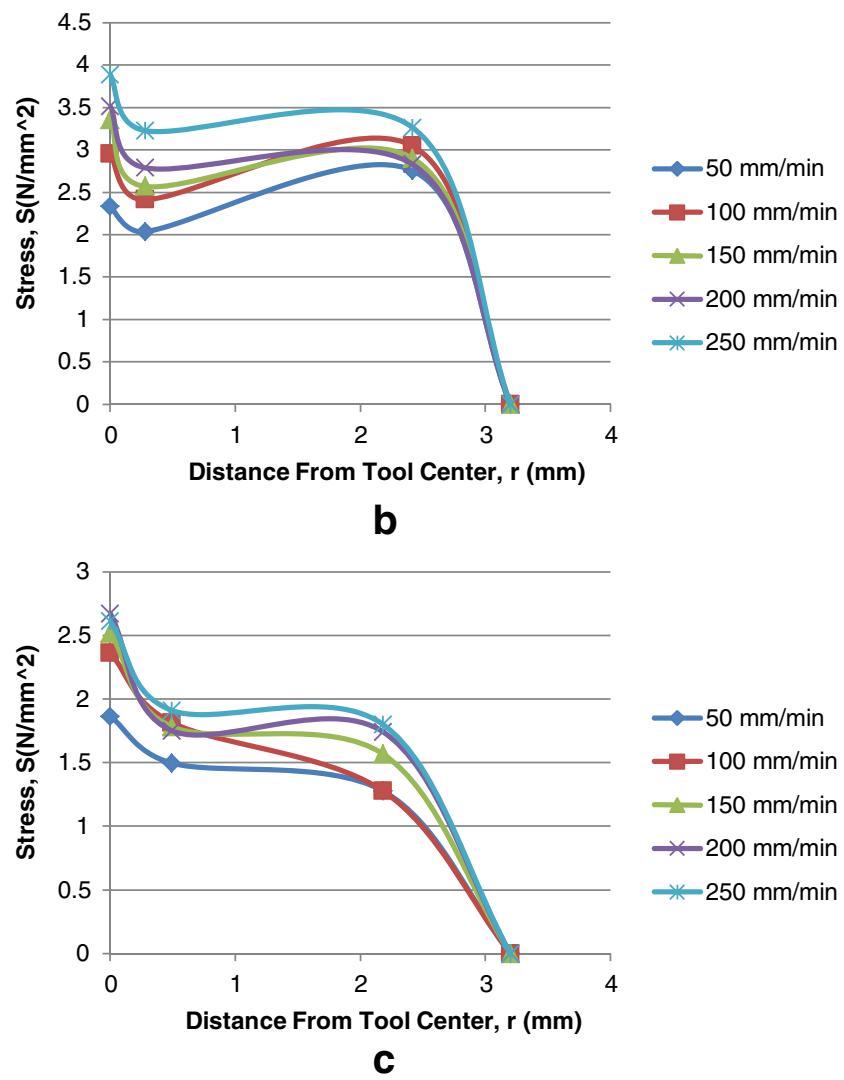

Fig. 12 Comparison of normal stresses $(S)$ on drilling edges calculated for $\mathbf{a} \mathrm{T} 1, \mathbf{b} \mathrm{T} 2$, and $\mathbf{c} \mathrm{T} 3$ for various feed rates

sequence. Due to its large chisel edge, drill T1 concentrates the normal stress at the hole center ( $r=0$ in Eq. 8$)$ and its long secondary drilling edge helps decrease the normal stress steeply towards the end of the process. Drill T3 exhibited the lowest normal stresses at the hole center, thanks to its chisel edge design, which includes a rake angle. Its normal stress distribution profile is similar to $\mathrm{T} 2$ but with lower normal stress values. They both employ the same design intent, i.e., long primary drilling edge. Normal stresses applied by the drill T2 are the largest as the secondary drilling edge leaves the hole.

The condition of the cutting edge is an important factor on drilling quality. In order to be able to further investigate the results, cutting edges of the drills were investigated after experiments by using a $3 \mathrm{D}$ laser scanning microscope 
(Keyence VKX 110). Figure 13 shows the edge profiles of secondary drilling edges of T1, T2, and T3. Figure 13 reveals that the secondary drilling edge of $\mathrm{T} 2$ is significantly worn after drilling the same number of holes as T1 and T3. Under the drilling conditions tested, abrasion is the main wear mechanism. The length of the wear land is around $100 \mu \mathrm{m}$. Drill T3 exhibited a smaller wear land compared to $\mathrm{T} 2$, whereas the cutting edge of drill $\mathrm{T} 1$ seems to be intact.

The edge radius of the fresh drills is measured to be around $12-15 \mu \mathrm{m}$. The reason why T2 exhibits a larger flank wear land can be related to its design intent, which tries to minimize the thrust force at the hole exit with a small chisel edge, which increases the torque intensity carried on the secondary cutting edge. It must also be noted that while significant wear exists on the secondary edge of $\mathrm{T} 2$, the thrust force and torque measurements are still similar to T1 and T3. In Fig. 1, for T2, it can be seen that the chisel edge length $(L)$ is considerably small, which also allows a small web thickness. However, a majority of the load has to be carried by the secondary edge, which probably leads to a faster wear on this edge. Drill T1 carries a significant portion of the thrust load on the chisel edge, thereby decreasing the thrust force intensities on the primary and secondary drilling edges. A short primary edge length results in longer secondary edge length, which allows for lower cutting force intensity on the secondary drilling edge. Drill T3 exhibits a similar design intent as $\mathrm{T} 2$, but its twist drill form allows for
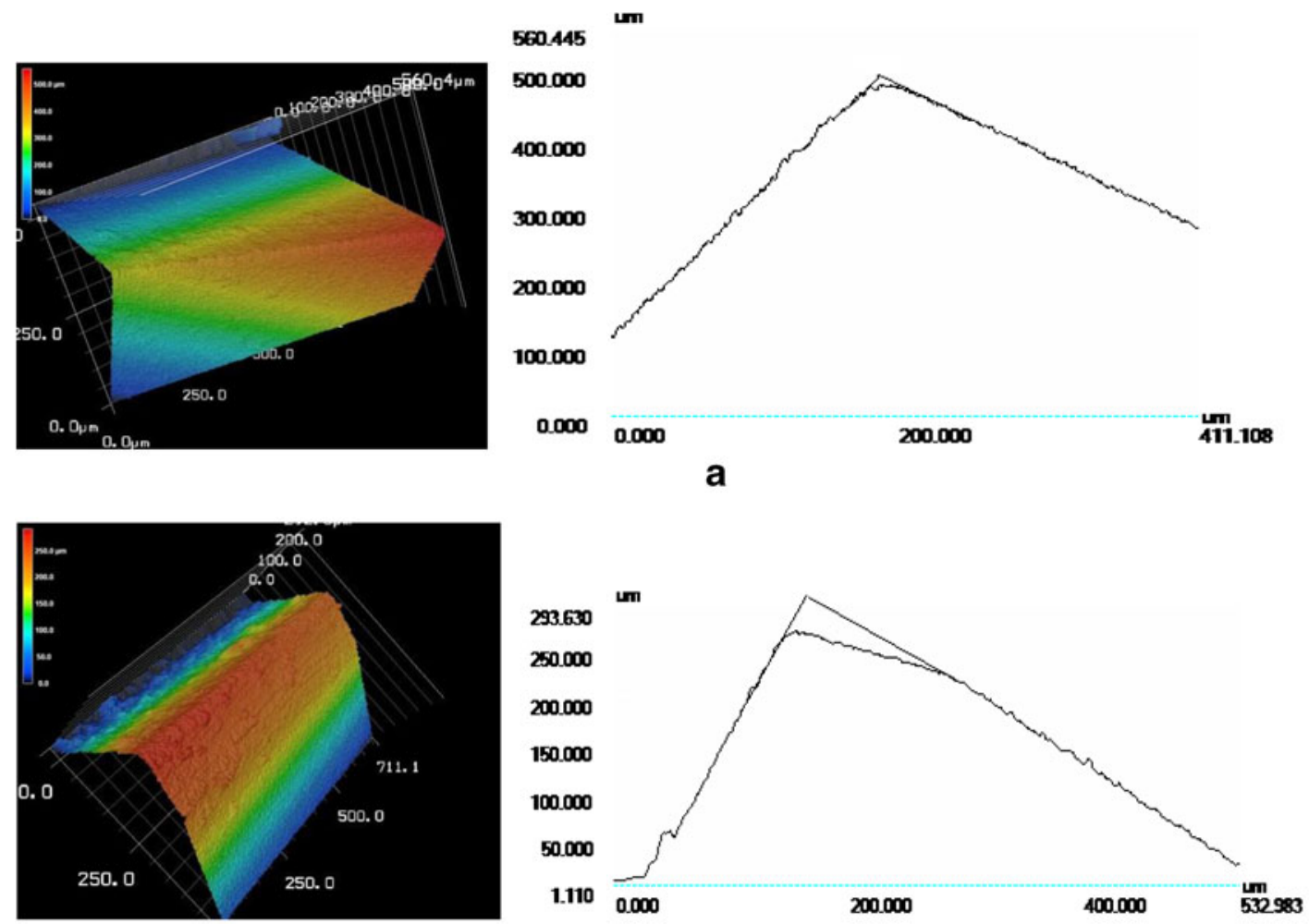

b
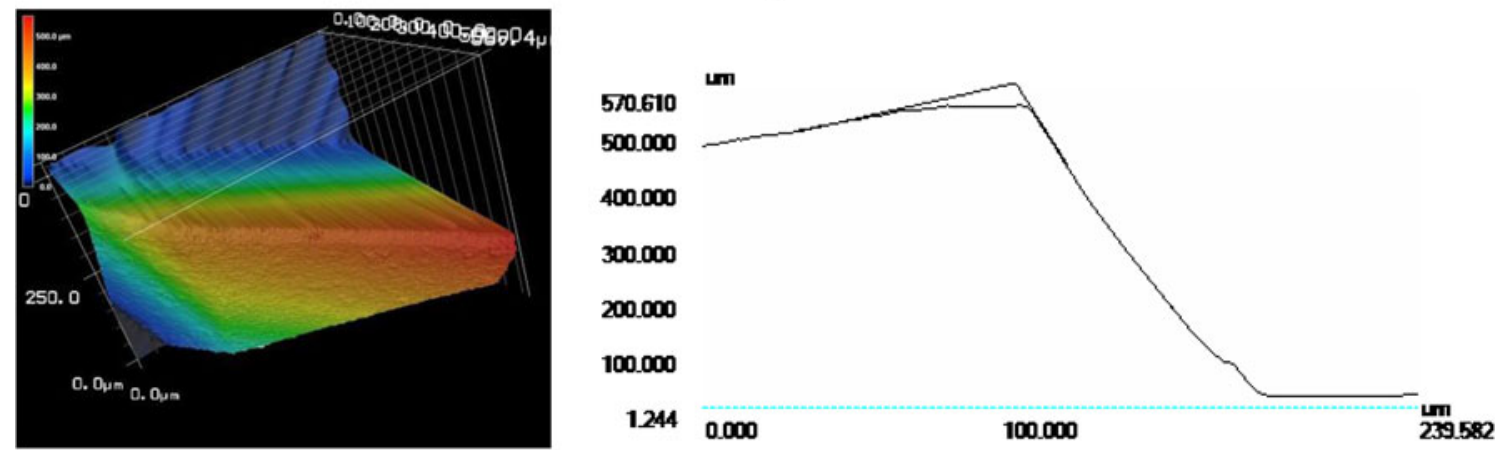

Fig. 13 Profiles of (fresh and worn) secondary drilling edges of a T1, b T2, and $\mathbf{c}$ T3 
better chip evacuation and its positive rake angle on the secondary drilling edge helps to reduce drilling forces. It yields comparable hole quality results to $\mathrm{T} 1$.

Figure 14a shows the variation of thrust force and torque for $\mathrm{T} 1$ at $100 \mu \mathrm{m} / \mathrm{rev}$ feed and 5,000 rpm (the CFRP laminate used in this particular experiment is 8-mm thick with same material properties). The variation of thrust forces between 1 st and $32 \mathrm{nd}$ hole can be seen in this figure. It must be noted that tool wear takes place in secondary drilling zone as it is obvious from the progress of the thrust force and torque measurements when the locations of point 3 of Fig. 4a are compared. Figure 14b shows the scanning electron microscope image of the wear land on the secondary drilling edge, which is similar to the wear land of $\mathrm{T} 2$ as observed in Fig. 13.
It must be noted that the influence of PCD material properties (grain size, percentage of cobalt/PCD, etc.) was not studied in this paper. Since PCD drills from different manufacturers were used in this study, some performance differences can also be related to the PCD material properties. Different drill geometries having the same PCD material properties fabricated by the same tool manufacturer may yield more detailed information about the process. Nevertheless, the trade-offs in drill design are clear as a result of the experimental study presented in this paper. There is a complex relationship between drill geometry design and its delamination performance. Additional experimental research is required to draw definite conclusions about these drill geometries. The results are in favor of a
Fig. 14 a Effect of tool wear on thrust force and torque. $\mathbf{b}$ Scanning electron microscope image of the wear land

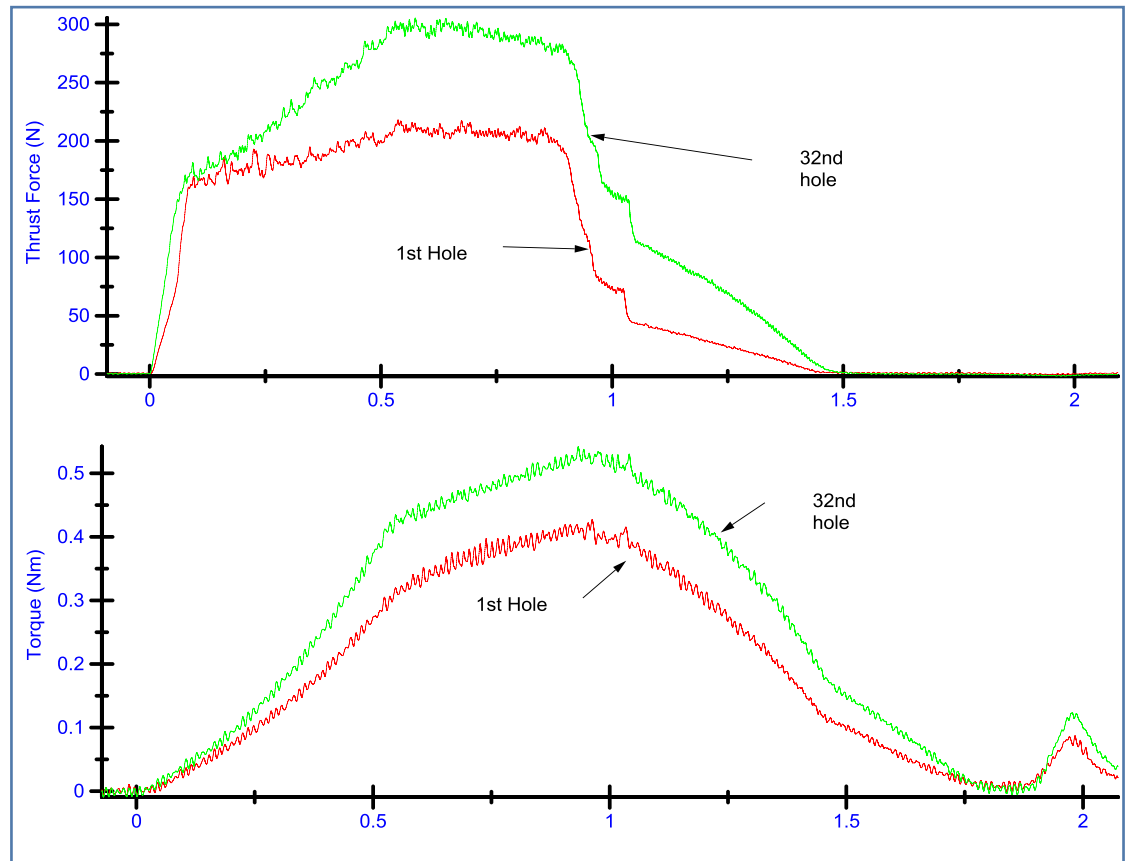

a
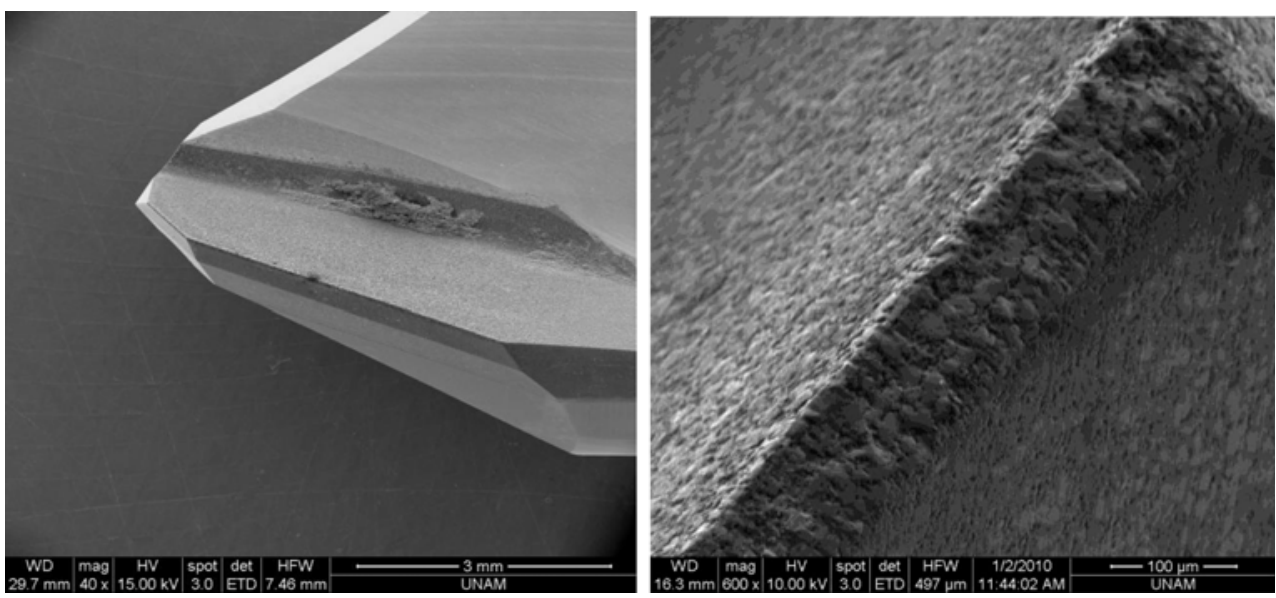

b 
long secondary drilling edge design, since lower tool wear was observed. However, it is important to note that a large secondary drilling edge increases the drilling time. Considering the total number of holes, longer drilling time may become an issue. In the case of drilling thin laminates, a long secondary drilling edge would exit the hole without tertiary drilling edge starting to drill. This results in an abrupt decrease in thrust force and torque, which adversely affects the quality of the hole. Therefore, a small chisel edge and a short secondary edge may work better in thin laminates.

\section{Conclusions}

In this study, drilling characteristics and performances of three PCD drills with different geometries were investigated. Experimental observations on drilling thick CFRP laminates showed that drill geometry parameters directly influence distribution of forces and torques among edges of the double point angle PCD drills. For the thick CFRP laminate used in this study:

- Drill designs T1 and T3 allowed drilling holes at higher feeds without delamination compared to drill design T2. Although drill T2 employed the smallest chisel edge design, it did not perform as well as T1 and T3. In general, small chisel edge drill designs are recommended to decrease thrust forces at the hole exit to decrease the likelihood of delamination. However, large chisel edge design may help to reduce thrust and cutting force intensities on the secondary drilling edge, which results in maintaining the sharpness of the cutting edge. Therefore, the relationship between secondary drilling edge tool wear and delamination must be investigated in more detail.

- Experimental investigations show that critical thrust force changes as a function of drill geometry, and for each drill geometry the critical thrust force is different.

- Instead of merely monitoring thrust forces at the last ply, investigation of normal stresses at the hole exit sequence may yield more insight about the process since the condition of the edges is reflected on the calculations.

Acknowledgments The authors would like to thank Scientific and Technical Research Council of Turkey (TUBITAK) for their financial support of this study.

\section{References}

1. Babikian R, Lukachko SP, Waitz IA (2002) The historical fuel efficiency characteristics of regional aircraft from technological, operational, and cost perspectives. J Air Transp Manag 8(6):389-400

2. Teti R (2002) Machining of composite materials. CIRP Ann Manuf Technol 51:611-634

3. Dandekar CR, Shin YC (2012) Modeling of machining of composite materials: a review. Int J Mach Tool Manuf 57:102-121

4. Park K, Beal A, Kim D, Kwon P, Lantrip PJ (2011) Tool wear in drilling of composite/titanium stacks using carbide and polycrystalline diamond tools. Wear 271(11-12):2826-2835

5. Montoya M, Calamaz M, Gehin D, Girot F (2013) Evaluation of the performance of coated and uncoated carbide tools in drilling thick CFRP/aluminum alloy stacks. Int J Adv Manuf Technol. doi:10. 1007/s00170-013-4817-0

6. Shyha IS, Aspinwall DK, Soo SL, Bradley S (2009) Drill geometry and operating effects when cutting small diameter holes in CFRP. Int J Mach Tool Manuf 49(12-13):1008-1014

7. Schulze V, Becke C, Weidenmann K, Dietrich S (2010) Machining strategies for hole making in composites with minimal workpiece damage by directing the process forces inwards. J Mater Process Technol 211(3):329-338

8. Piquet R, Ferret B, Lachaud F, Swider P (2000) Experimental analysis of drilling damage in thin carbon/epoxy plate using special drills. Compos A 31:1107-1115

9. Lazar MB, Xirouchakis P (2011) Experimental analysis of drilling fiber reinforced composites. Int J Mach Tool Manuf 51(12):937-946

10. Faraz A, Biermann D, Weinert K (2009) Cutting edge rounding: an innovative drill wear criterion in drilling CFRP composite laminates. Int J Mach Tool Manuf 49:1185-1196

11. Tsao CC (2008) Thrust force and delamination of core-saw drill during drilling of carbon fiber reinforced plastics (CFRP). Int J Adv Manuf Technol 37(1-2):23-28

12. Hocheng H, Tsao CC (2006) Effects of special drill bits on drillinginduced delamination of composite materials. Int J Mach Tool Manuf 46(12-13):1403-1416

13. Tsao CC, Chen WC (1997) Prediction of the location of delamination in the drilling of composite laminates. J Mater Process Technol 70: $185-189$

14. Tsao CC, Hocheng H (2003) The effect of chisel length and associated pilot hole on delamination when drilling composite materials. Int J Mach Tools Manuf 2003(43):1087-1092

15. Won MS, Dharan CHK (2002) Chisel edge and pilot hole effects in drilling composite laminates. Trans ASME J Manuf Sci Eng 124: 242-247

16. Karpat Y, Değer B, Bahtiyar O (2012) Drilling thick fabric woven CFRP laminates with double point angle drills. J Mater Process Technol 212(10):2117-2127

17. Lachaud F, Piquet R, Collombet F, Surcin L (2001) Drilling of composite structures. Compos Struct 52:511-516

18. Durao LMG, Gonçalves DJS, Tavares JMRS, de Albuquerque VHC, Vieira AA, Marques AT (2010) Drilling tool geometry evaluation for reinforced composite laminates. Compos Struct 92(7):1545-1550

19. Tsao CC, Hocheng H (2004) Taguchi analysis of delamination associated with various drill bits in drilling of composite material. Int $\mathrm{J}$ Mach Tools Manuf 2004(44):1085-1090 